\title{
Organization of Probabilistic Expert Estimates Collection and Interpretation in Political Forecasting
}

\author{
Dmitriy Alpackiy \\ Bauman Moscow State Technical University \\ 5/1, 2nd Baumanskaya St. \\ Moscow, Russia 105005 \\ E-mail: alpacky@mail.ru
}

\author{
Irina Alpackaya \\ National Research University \\ Moscow State University of Civil Engineering \\ 26, Yaroslavskoe road \\ Moscow, Russia 129337 \\ E-mail: alpackaya-irina@mail.ru
}

\author{
Anastasia Kolosova \\ Moscow State Linguistic University \\ 38, Ostozhenka St. \\ Moscow, Russia 119034 \\ E-mail: kolosova.an.va@gmail.com
}

\begin{abstract}
The purpose of the proposed article is to study the probabilistic approach to political forecasts, obtained from experts' survey. The article describes expert information collection characteristic features, in particular, the networking: for obtaining probabilistic estimates of specialists. Especially the paper considers the different ways of interpreting these estimates. The author concludes that not only forecasting methods play an essential role in scientific forecast, (although obtained estimates values depend on the correctly chosen data and information collecting professional method), but also the obtained prognostic probabilities interpretation.
\end{abstract}

Keywords—expert estimates; probability; political forecasting; political forecast; network expertise

\section{INTRODUCTION}

Increasingly, the country's leadership faces uncertainty in setting strategic objectives. In such situations, the forecast as an element of the triad «forecasting - planning management» plays a special role. Political forecasts are the basis for rational decision-making; this is spelled out in regulatory and legal acts, for example, the strategic planning main stages, in accordance with the Federal Law «On Strategic Planning in the Russian Federation [1], directly involve planning. V.V. Putin in the decree «On national goals and strategic tasks of the development of the Russian Federation for the period up to 2024» sets before the Government the task of creating a socio-economic forecast for the Russian Federation development up to 2024 [2].

The purpose of the article is to identify the probabilistic nature of interpretation features in expert assessments in political forecasting. The following problems solution will contribute to the achievement of this goal: 1) to identify promising technologies for obtaining expert estimates; 2) to determine the political forecasts interpretation features for effective decision-making.

\section{USING THE EXPERT ASSESSMENT METHOD FOR FORECAST CREATION}

Forecasts are always associated with random processes that cannot be eliminated for many reasons; therefore, in many cases they are tools for solving uncertainties.

The term "forecast" interpretations somewhat differ, for example, the Committee on Scientific and Technical Terminology of the Academy of Sciences in 1990 proposed the following definition: "forecast - scientifically grounded judgment on possible state of the object in the future and (or) alternative ways and terms of achieving it"[3]. M.A. Timofeeva, summarizing the approaches to the concept of "forecast", concludes that it must satisfy the following requirements: firstly, to have a probabilistic character; secondly, to be scientifically grounded; thirdly, to determine the object state in the future, as well as alternative ways and terms for achieving it; fourthly, to contain a certain time indication [4]. A variant for obtaining political forecasts is experts' assessments that reflect the experts' individual judgments regarding the object development prospects. The basis for this kind of forecast is professional experience and intuition. M. Polanyi in the study of scientific knowledge process as universe objective connections comprehension (given the exceptional constructive role of the knowledge process subject) touches upon the skills that experts demonstrate in various fields. He concludes that: "in the very heart of science there are practical knowledge areas that cannot be transmitted through language" [5]. V.M. Rusalov in his study showed that human probabilistic-prognostic activity has formal-dynamic self-regulation features. As an intellectual activity model, he used a probabilistic learning binary model, while for the analysis, he worked out 29 selfregulation parameters. In his opinion, the main activity factors in probabilistic environments are the mental processes speed and verbal intelligence [6]. 
In general, collective expert assessments methods are attributed to the intuitive-logical group, as apart from the expert experience and intuition already mentioned, this group demonstrates the established logical procedure for research, but with a relatively small forecasting object formalization degree [7, 8].

In the scientific literature, there are three main types of tasks that the expert commissions solve:

- Existing objects evaluation (measurement)

- Objects construction.

- Objects construction and their evaluation.

Depending on the goals and tasks set, there will be a need for various expert commissions. We cannot give some general recommendations on how to form the expert groups', but if we are talking about an "unbiased" conclusion working out, it is reasonable to attract the most highly qualified specialists in this field. Most often, the decision to engage an expert is based on his professional characteristics study, for example, the length of service and quality of work in this field, or on his competence evaluation by others $[9,10]$.

There are four main types of procedures for obtaining information by expert commissions: one-round ones with direct experts' interaction; one-round without direct experts' interaction; iterative with direct experts' interaction; iterative without direct experts' interaction. Depending on the chosen procedure type, various methods will be applied. For the first type (a one-round procedure with direct experts' interaction), we observe the "brainstorming" method, which consists in holding a joint experts meeting on certain rules aimed at creating a free judgments expression atmosphere. Critical is the experts' refusal to attack the statement during the meeting; in this sense, the feedback mechanism is absent, and the procedure is one-round. The second type (a oneround procedure without direct experts' interaction) involves conducting a one-time real survey of unrelated experts. This technique is quite convenient. However, its use is justified only when the survey is conducted as soon as possible and at the lowest cost. To the third type (an iterative procedure with direct experts` interaction) we attribute the traditional "round table discussion", which has been used for a long time and is widely used in practice. During the discussion, each expert has the opportunity to repeatedly make judgments, change and clarify his point of view, taking into account other experts' opinions. The experts can hold the discussion during some clearly defined tours. To this method advantages we can attribute the operational feedback, the presence of nonverbal contacts, the rapid misunderstanding between experts overcoming (for example, terminological).

The disadvantages are: the major authorities' judgments strong influence, the individual experts' susceptibility to the majority opinion, the unwillingness to openly reconsider the judgment already expressed. Psychologists who studied the participants' behavior in the discussion, found out the phenomenon of "group mentality" danger [11]. It arises when, despite the group members' high intelligence, they abandon the critical, realistic style of thinking for the unanimity, mixed with excessive conviction in the group work success [12].

To the fourth type (an iterative procedure without direct experts' interaction), we can attribute the network expertise [13]. Under the network expertise, in our opinion, it is necessary to understand an object, a situation, a question requiring expert knowledge research, whose organizational structure is based on the information and communication technologies, with a motivated conclusion necessary for making an administrative decision [14].

The network expertise has several advantages [15]:

- Problem coverage efficiency, accuracy and completeness;

- Experts`opinions representability;

- The perspective of many experts`involvement, each of whom may be a specialist in the issues under consideration;

- Direct communication possibility between experts or vice versa, each expert in the group does not interact with others, but sees their work result; The possibility to document and process in real time various communication nuances that can reflect the certain actions sense;

- Transparency, openness and responsibility, or complete anonymity, but with the responsibility retention.

Thus, to date, there are many sufficient methods for collecting and analyzing expert assessments when creating political forecasts. The methods presented in the scientific literature have a sufficiently diverse mathematical apparatus, which makes it possible to obtain probabilistic estimates. For the correct expert opinion interpretation, when making a political decision based on it, which undoubtedly must be scientifically grounded, it is important to understand the essence of the political forecast probabilistic nature [16].

\section{INTERPRETATION OF EXPERT ESTIMATES PROBABILISTIC CHARACTER}

The emergence of theoretical-probabilistic cognition methods revolutionized the scientific thinking and transformed the doctrine of causality. The idea of probability shook the rigid determination concept, inherent to the science development classical stage. In turn, this concept has expanded the world view and cognition in general [17]. The classical definition of probability in mathematics is based on the fact that there is a space of elementary outcomes $\Omega$ that contains a finite number of elementary outcomes, all of which are equally possible. $\mathrm{N}_{\mathrm{A}}$ is the number of elementary outcomes forming event A (sometimes called beneficial for A). In this case, the probability of an event $\mathrm{A}$ is the ratio of the number of event-favorable elementary outcomes to the total number of equally possible elementary outcomes [18], i.e.

$$
P(A)=\frac{N_{A}}{N} .
$$


A.N. Kolmogorov in his paper "Basic concepts of probability theory" suggests the following scheme for applying the theory of probability to data.

- Data complex that allows an unlimited number of repetitions.

- Study of a certain range of events.

- Under certain conditions events A are assigned some real numbers from zero to one [19].

I.I. Gurevich, I.M. Feigenberg raise an issue of correctness of using the classical probability understanding in predicting human activity. They note that the phenomena measurement results refer to the "observable-observer" complex, where the result may change with a change in the observation method. In their opinion, in psychology it is more appropriate to use the concept of the probability amplitude, borrowed from quantum physics [20]. Political sciences also cannot use the classical probability interpretation, because in this case, the use is possible only with unlimited repetitions. Political events do not repeat many times and to conduct the experiment (except in the model, but with significant limitations) is impossible.

In the political forecasts construction, an epistemological interpretation of probability is most often used [21]. In this case, the probable statement will look like this. The probability that a is $\mathrm{B}$ is approximately equal to $\mathrm{p}$, providing that, with respect to the modern political knowledge system, $\mathrm{a}$ is a random member of some class $\mathrm{A}$ with respect to belonging to class $\mathrm{B}$ and providing that knowledge allows us to state that the fraction $\mathrm{B}$ in $\mathrm{A}$ is close to $\mathrm{p}$ [22]. This probability type example can be I.K. Kharychkin and T.S. Oruyova`s conclusion regarding the likelihood of reaching a qualitatively new cooperation level between Russia and Iran [23]. Often, when creating political forecasts, probability empirical interpretation is used. This type exists in three versions: probability is identified with the relative frequency; probability is considered as an abstract double of relative frequency; probability is considered as the certain events types' characteristic [21]. For example, the prediction of this type is to calculate the postgraduate students' progress probability in the following years [24].

Speaking about the probability it is impossible to avoid the issue of randomness and determinism. M. Bunge considers the classical problem of probability theory - coin tossing. In his opinion, the appearance of a "head" after tossing a coin is by no means an irregular event and by no means, arising from nothing. Only this is not the only possible result, it is possible that the "head" or "tails" fall out.

M. Bunge believes that throwing a coin is a deterministic process, since a combination of certain conditions is required: the presence of a coin, gravity, surface, etc.; there are no arbitrary, irregular results, throwing a coin gives only the fall of the "head" or "tails" [25]. Causality, in his view, is not identical to predictability.

I. Prigogine and I. Stengers challenge this approach; they argue that the deterministic view of chemistry ceases to work. When the system reaches the bifurcation point, the deterministic description becomes unsuitable. Further evolution of the system will occur along the way which fluctuation will force to choose. The coin toss and the transition through bifurcation are random processes examples. I. Prigogine and I. Stengers are proposing to call the situation that arises after the effect of fluctuations on the system - 'the order through fluctuation' [26].

E.V. Suslov gives an example of the political oversight of W. Wilson in the formulation of the so-called "14 Wilson`s points". While developing them, he proceeded from deterministic postulates, but the new sovereign states immediately found themselves in a state of conflict with each other [27].

A significant number of political scientists are engaged in the search of factors that can affect the state political system or international relations [28]. So Yu.V. Sinchuk, while studying contemporary challenges for the Russian Federation, identifies the threats that could well lead to qualitative geopolitical changes, in other words, to be the fluctuations of the international political system [29].

\section{CONCLUSION}

Thus, political forecasts are probabilistic in nature. The forecasts accuracy depends on many factors. The main ones are: firstly, the type of procedure for obtaining experts' estimates. To date, network methods of expertise stand out in a positive way. Secondly, the correct goals and objectives setting to experts. Political issues are many-sided and require various profiles specialists' involvement; it is important that they should treat the issues posed to them identically. Thirdly, despite the digital data obtaining after an expert assessment, it is necessary to interpret correctly the probabilities obtained. In some cases, the results interpretation may radically differ from the classical mathematical approach.

\section{REFERENCES}

[1] On strategic planning in the Russian Federation [Electronic resource] Federal Law of the Russian Federation no. 172, June 24, 2014. Access from the Consultative Plus reference system.

[2] On the national goals and strategic objectives of the development of the Russian Federation for the period up to 2024 [Electronic resource] Presidential Decree no. 204, May 7, 2018. Access from the Consultant Plus reference system.

[3] The forecast. Terminology, Moscow, Nauka Publ., 1990.

[4] Timofeeva M.A. Experience of political forecasting in the USA and Russia, Dis. Cand., Sc., 23.00.02, St. Petersburg, 2005.

[5] Polanyi M. Personal knowledge: Towards a post critical philosophy, trans. from English, ed. Lectorsky V. A., Arshinov V. I, foreword V. A. Lectorsky, Moscow, Progress Publ., 1985.

[6] Rusalov V.M. Biological basis of individual psychological differences, Moscow: Nauka Publ., 1979.

[7] Kokoshin A.A. Forecasting and Policy. Methodology, organization and use of international forecasting relations in the external policy of the USA. Institute for US and Canadian Studies, the USSR Academy of Sciences, ed. Dr. Sc.., Trofimenko G.A, International Relations Publ., 1975, 176 p.

[8] Oseledchik M.B., Ivlev V.Yu., Ivleva M.L. Knowledge as a nonequilibrium dynamic system // "Proceedings of the 2017 2nd International Conference on Contemporary Education, Social 
Sciences and Humanities". (ICCESSH 2017). Part of the series ASSEHR. Moscow, Russia. V/124. P.1-5.

[9] Beshelev S.D., Gurvich F.G. Expert assessments, Moscow, Nauka Publ., 1973.

[10] Arab-Ogly E. A., Bestuzhev-Lada I.V., Gavrilov N.F. et al. Working book on forecasting, ed. Bestuzhev-Lada I. V., Moscow, Mysl Publ., 1982.

[11] Gubanov N.I., Gubanov N.N. The role of mentality in the development of society: sociocultural hypothesis // Vestnik slavianskikh kultur-bulletin of slavic cultures-scientific and informational journal. 2017. Vol. 43. № 1. P. 38-51.

[12] Yanch E. Prediction of scientific and technical progress, Moscow, Progress Publ., 1970.

[13] Oseledchik M.B., Ivlev V.Yu., Ivleva M.L. Using social networks in knowledge management system //Proceedings of the 2nd International Conference on Culture, Education and Economic Development of Modern Society (ICCESE 2018). Moscow, Russia. Pp.911-914.

[14] Kolosova A.V. Network models in political design. Analytical technologies in the social sphere: theory and practice. Moscow, EkonInform Publ., 2018, pp. 11-13.

[15] Gubanov D.A., Korgin N.A., Novikov D.A. Models of fuzzy network expertise. Control Systems and Information Technology, 2010, no. 4, pp. 13-18.

[16] Zemtsov B.N. Right as World Outlook Value of the Power (XX Century) // Tomsk State university journal of history. 2014. № 4 (30). P. 28-34.

[17] Satchkov Yu.V. Spontaneity and Determinism, monogram, RAS, Institute of Philosophy, Moscow, Science, 2006

[18] Probability Theory [Proc. for universities]. Pechkin A.V, Teskin O.I., Tsvetkova G.M. et al.; ed. Zarubina V.S., Krishchenko A.P., Bauman Moscow State Technical University Publ., 2006.

[19] A.N. Kolmogorov Basic concepts of probability theory [Text]. 2nd ed. Moscow, Nauka Publ., 1974.

[20] Gurevich I.I., Feigenberg I.M. What are the probabilities of "working" in psychology? In the collection: Probabilistic forecasting in human activity, Moscow: Nauka Publ., 1977.

[21] Lebedev S.A. The Reassembly of the Epistemology // Voprosy filosofii. 2015. № 6. P. 53-64.

[22] G. Kaiberg Probability and Inductive Logic, Moscow, Progress Publ., 1978.

[23] Kharychkin I.K., Orujova T.S. Political and economic cooperation between Russia and Iran at the present stage. Cooperation between Russia and Iran in political, economic and cultural spheres as a factor of strengthening peace and security in Eurasia, Moscow, Moscow State Linguistic University Publ., 2017, pp. 120-124.

[24] Alpatsky D.G. The state policy of the Russian Federation in the sphere of higher technical education. Dis. Cand., Sci., (Politics), 23.00.02, Moscow, 2014.

[25] Bunge M. Causality: The place of the causality principle in modern science, Moscow, Foreign Literature Publishing House Publ., 1962.

[26] Prigogine I., Stengers I. Order from chaos: a new dialogue between man and nature, Moscow, Progress Publ., 1986.

[27] Suslov E.V. Synergetic paradigm in the study of modern political processes - Vestnik of Mari State University, 2016, vol. 2, no. 4 (8), pp. 86-93.

[28] Suzdaleva T.R. Migratory processes in the context of geopolitics // Vestnik Tomskogo gosudarstvennogo universiteta-Filosofiyasotsiologiya-politologiya-Tomsk state university journal of philosophy sociology and political science. 2016. № 3 (36). P. 237244. DOI: $10.17223 / 1998863 \mathrm{X} / 35 / 25$

[29] Sinchuk Yu.V. Modern Challenges and Threats of the Russian Federation - Bulletin of Moscow State Linguistic University, no. 25(631), pp. 201-220. 